\title{
JEKK
}

Jurnal Epidemiologi Kesehatan Komunitas

$2(2), 2017,62-68$

\section{Berbagai Faktor yang Berpengaruh Terhadap Kejadian Rawat Inap Jemaah Diabetes Melitus di Arab Saudi (Studi Kasus Kontrol di Embarkasi Adisumarmo)}

\author{
Rakhamanto Wahyu Nugroho ${ }^{*}$, Suharyo Hadisaputro ${ }^{* *}$, Widiastuti Samekto ${ }^{* * *}$, Sugiri ${ }^{* * *}$, Djoko \\ Trihadi Lukmono***** \\ *Kantor Kesehatan Pelabuhan Semarang, ${ }^{* *}$ Politeknik Kesehatan Semarang, ${ }^{* * *}$ RSUP Dr. Kariadi \\ Semarang, ${ }^{* * * *}$ RSI Sultan Agung Semarang
}

\begin{abstract}
Background : Given the magnitude of high-risk DM throughout Hajj embarkation and pilgrims hospitalization in Saudi Arabia, we need for prevention and control of DM pilgrims hospitalization case in Saudi Arabia. To prevent and control the incidence of hospitalization, public and the government needs to know the various factors that influence the incidence of hospitalization.

Methods : The study was observational with case control study design. The study population is the assembly of DM in Adisumarmo Hajj embarkation. Number of samples of 135 people with 45 cases and 90 controls. The dependent variable is inpatient diabetic in Saudi Arabia, the independent variable is demographics (age, gender, education level), comorbidities (hypertension, heart disease, dyslipidemia, stroke, obesity), behavior (compliance with diet and medication), the knowledge, long suffered diabetic, environment (temperature and duration in Saudi Arabia.

Results : Most respondents had long suffered from diabetes. The level of compliance of respondents to the diet DM and DM medication adherence is good. Multivariate factors that influence the incidence of hospitalization DM pilgrims in Saudi Arabia is a dietary adherence $(\mathrm{p}=0.001, \mathrm{OR}=14,95 \% \mathrm{CI}=2.78$ to 70.97$)$ and knowledge $(\mathrm{p}=0.003, \mathrm{OR}=6.5 ; 95 \%$ $\mathrm{CI}=0.59$ to 4.51$)$.
\end{abstract}

Conclusion : Factors that influence the incidence of DM pilgrims hospitalization in Saudi Arabia is a dietary adherence and knowledge.

Keywords: Factors; hospitalization DM; pilgrims; Saudi Arabia

Penulis korespondensi : nugrohorakhmanto@gmail.com 


\section{Pendahuluan}

Minat masyarakat untuk berangkat haji demikian tinggi, berdasarkan catatan dari tahun 2001 sampai 2013, calon pendaftar jemaah haji Indonesia mencapai 4.998.499 orang. Rata-rata jumlah pendaftar mencapai 40.000 orang per bulan. ${ }^{1}$ Bahkan berdasarkan daftar tunggu, ada yang mencapai daftar tunggu sampai dengan tahun 2041 (Provinsi Kalimantan Selatan). ${ }^{2}$ Berdasarkan hal tersebut, diperlukan pengelolaan status kesehatan yang baik bagi para calon jemaah haji, agar dalam pelaksanaan ibadah nantinya tidak terganggu oleh buruknya kondisi kesehatan. Salah satu persoalan kesehatan dalam penyelenggaraan haji adalah tingginya risti jemaah DM di seluruh embarkasi haji.

Pada penyelenggaraan ibadah haji tahun 2012 dan 2013, DM merupakan kasus risti yang sering dijumpai. Bahkan dalam kasus kejadian rawat inap di Arab Saudi, DM menempati peringkat pertama. ${ }^{3}$ Untuk menanggulangi meningkatnya kasus rawat inap DM di Arab Saudi, maka masyarakat maupun pemerintah perlu mengetahui faktor-faktor yang mempengaruhi kejadian rawat inap jemaah DM.

Berdasarkan penelitian di berbagai negara, beberapa faktor yang berpengaruh terhadap kejadian rawat inap adalah faktor demografi seperti usia lanjut, tingkat pendidikan rendah, dan jenis kelamin lakilaki. Namun beberapa faktor tersebut masih menjadi perdebatan, dikarenakan hasil yang berbeda pada penelitian lainnya, termasuk faktor komorbid penyakit lainnya. Selain itu, penelitian-penelitian sebelumnya lebih banyak terfokus pada DM tipe 2 dan dilakukan pada responden yang tinggal menetap. Oleh karena itu, perlu diketahui Saudi, yang respondennya tidak tinggal menetap/dalam perjalanan (ibadah haji).

\section{Metode}

Jenis penelitian yang dilakukan merupakan penelitian epidemiologi yang bersifat observasional analitik dengan desain case control. Populasi studi dikelompokkan menjadi dua yaitu kasus dan kontrol. Kasus adalah jemaah DM yang memerlukan rawat inap di Arab Saudi dan sudah dientry dalam aplikasi Siskohatkes. Kelompok kontrol adalah jemaah DM yang tidak menjalani rawat inap di Arab Saudi dan berada satu kloter dengan kasus. Penelitian ini menggunakan total sampling yaitu mengambil keseluruhan jumlah kasus yang ditemukan berdasarkan kriteria inklusi dan eksklusi.

Dalam kurun waktu pelaksanaan embarkasi ditemukan 45 kasus (jemaah DM rawat inap di Arab Saudi) yang sesuai dengan kriteria penelitian, dengan perbandingan kasus:kontrol $=1: 2$, maka dalam penelitian ini ditentukan jumlah sampel kasus: kontrol $=45: 90$, sehingga total responden berjumlah 135 orang.

Variabel dikelompokkan menjadi dua yaitu variabel terikat adalah kejadian rawat inap jemaah DM di Arab Saudi. Sedangkan, variabel bebas adalah usia, jenis kelamin, tingkat pendidikan, pengetahuan, lama DM, komorbid: hipertensi, penyakit jantung, dislipidemia, riwayat stroke, dan obesitas, kepatuhan diet, kepatuhan pengobatan, lama hari sebelum rawat inap dan suhu di Arab Saudi.

\section{Hasil}

Jemaah Embarkasi SOC tahun 2014 sebanyak 26.433 termasuk di dalamnya sejumlah 355 petugas yang terdiri dari petugas TKHI ( 1 petugas medis dan 2 paramedis), 1 petugas TPHI dan 1 petugas TPIHI dalam setiap kloter. Jemaah yang mempunyai risti DM berjumlah 2.718 orang, 48 orang diantaranya sempat 
menjalani rawat inap di Arab Saudi dan 3 orang meninggal di Arab Saudi ${ }^{4}$, sehingga jemaah yang memenuhi kriteria sebagai kasus 45 orang.

Jumlah responden direncanakan sebanyak 135 orang terdiri dari 45 kasus dan 90 responden. Setelah dilakukan penelusuran terdapat 5 orang kasus yang telah meninggal dunia, dan 21 orang responden tidak bisa ditemui dengan sebab karena pindah alamat ataupun tidak berada di tempat. Empat orang kasus yang meninggal masih dapat diambil data praktek diet dan pengobatan dikarenakan pada saat berangkat haji didampingi oleh pasangan (suami/istri) maupun keluarga yang lain.

Berdasarkan tempat tinggal, 132 responden berasal dari Provinsi Jawa Tengah dan 3 orang responden berasal dari Provinsi DIY.

Tabel 1. Hasil analisis bivariat

\begin{tabular}{|c|c|c|c|c|c|c|c|c|}
\hline \multirow{2}{*}{ No } & \multirow{2}{*}{\multicolumn{2}{|c|}{ Variabel }} & \multicolumn{2}{|c|}{ Kasus } & \multicolumn{2}{|c|}{ Kontrol } & \multirow{2}{*}{ Nilai $p$} & \multirow{2}{*}{ OR $(95 \% \mathrm{CI})$} \\
\hline & & & $\mathrm{n}$ & $\%$ & $\mathrm{n}$ & $\%$ & & \\
\hline \multirow[t]{2}{*}{1.} & Usia & $\leq 59$ th & 25 & 55,6 & 55 & 61,1 & 0,53 & $1,25(0,6-2,5)$ \\
\hline & & $\geq 60$ th & 20 & 44,4 & 35 & 38,9 & & \\
\hline \multirow[t]{2}{*}{2.} & Jenis kelamin & Laki-laki & 17 & 37,8 & 32 & 35,6 & 0,8 & $1,1(0,5-2,3)$ \\
\hline & & Perempuan & 28 & 62,2 & 58 & 64,4 & & \\
\hline \multirow[t]{2}{*}{3.} & $\begin{array}{l}\text { Tingkat } \\
\text { pendidikan }\end{array}$ & $\begin{array}{l}\text { SD, SMP, } \\
\text { SMA }\end{array}$ & 36 & 80 & 59 & 65,6 & 0,077 & $2,1(0,8-4,9)$ \\
\hline & & $\mathrm{D} 3, \mathrm{~S} 1, \mathrm{~S} 2$ & 9 & 20 & 31 & 34,4 & & \\
\hline \multirow[t]{2}{*}{4.} & Pengetahuan & Kurang & 25 & 83,3 & 41 & 51,9 & 0,002 & $4,6(1,6-13,3)$ \\
\hline & tentang DM & Baik & 5 & 16,7 & 38 & 48,1 & & \\
\hline \multirow[t]{2}{*}{5.} & $\begin{array}{l}\text { Lama } \\
\text { menderita }\end{array}$ & $\geq 9$ th & 27 & 75 & 46 & 58,2 & 0,078 & $2,1(0,8-5,1)$ \\
\hline & DM & $\leq 8$ th & 9 & 25 & 33 & 41,8 & & \\
\hline \multirow[t]{3}{*}{6.} & Kepatuhan & Tidak patuh & 12 & 33,3 & 4 & 5,1 & $<0,001$ & $9,1(2,6-30,9)$ \\
\hline & & Patuh & 24 & 66,7 & 73 & 92,4 & & \\
\hline & & $\begin{array}{l}\text { Sangat } \\
\text { patuh }\end{array}$ & 0 & 0 & 2 & 2,5 & & \\
\hline \multirow[t]{3}{*}{7.} & Kepatuhan & Tidak patuh & 13 & 36,1 & 11 & 13,9 & 0,029 & $3,5(1,3-9,04)$ \\
\hline & pengobatan & Patuh & 22 & 61,1 & 66 & 83,5 & & \\
\hline & & $\begin{array}{l}\text { Sangat } \\
\text { patuh }\end{array}$ & 1 & 2,8 & 2 & 2,5 & & \\
\hline \multirow[t]{2}{*}{8.} & Komorbid & Ya & 22 & 48,9 & 48 & 53,3 & 0,62 & $0,8(0,4-1,7)$ \\
\hline & hipertensi & Tidak & 23 & 51,1 & 42 & 46,7 & & \\
\hline \multirow[t]{2}{*}{9.} & Komorbid & $\mathrm{Ya}$ & 9 & 20 & 11 & 12,2 & 0,23 & $1,7(0,6-4,7)$ \\
\hline & $\begin{array}{l}\text { penyakit } \\
\text { jantung }\end{array}$ & Tidak & 36 & 80 & 79 & 87,8 & & \\
\hline \multirow[t]{2}{*}{10.} & Komorbid & $\mathrm{Ya}$ & 8 & 17,8 & 8 & 8,9 & 0,14 & $2,2(0,7-6,3)$ \\
\hline & dislipidemia & Tidak & 37 & 82,2 & 82 & 91,1 & & \\
\hline \multirow[t]{3}{*}{11.} & Komorbid & Pernah 2 & 1 & 2,2 & 0 & 0 & 0,15 & $8,1(-)$ \\
\hline & riwayat & kali & & & & & & $3,4(-)$ \\
\hline & stroke & Pernah & 2 & 4,4 & 1 & 1,1 & & \\
\hline
\end{tabular}




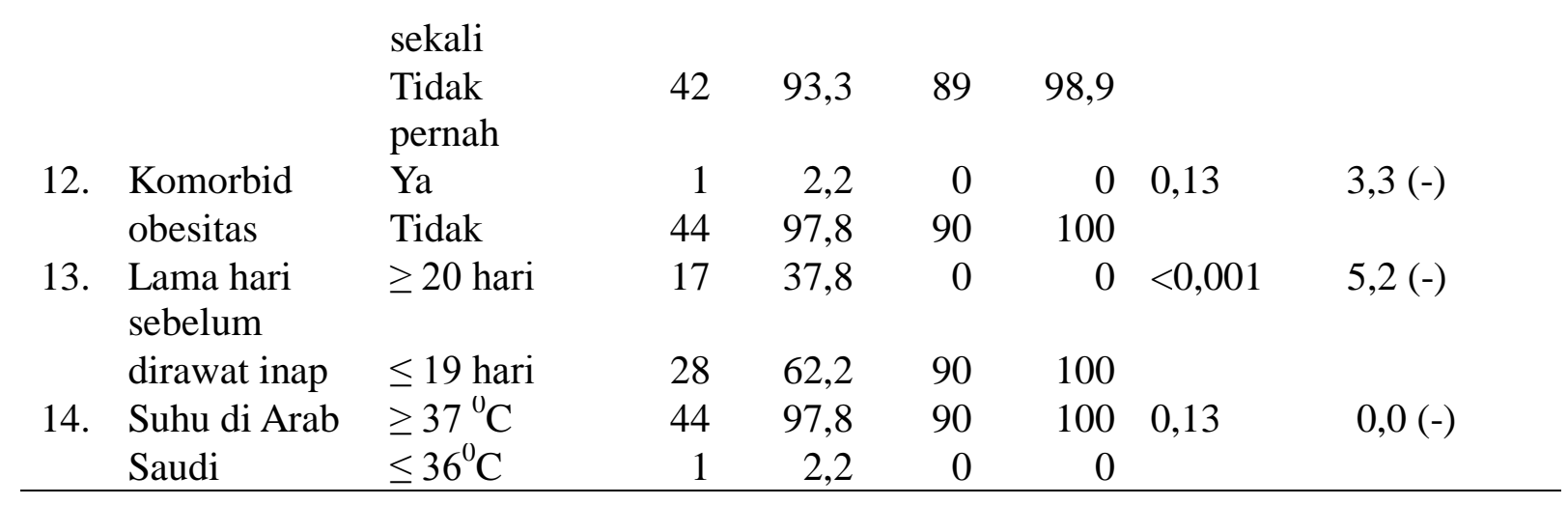

Dari hasil analisis bivariat, usia secara statistik tidak berpengaruh terhadap kejadian rawat inap jemaah DM di Arab Saudi $(p=0,53)$. Namun, dari hasil penelitian ini dapat disimpulkan bahwa usia risti mempunyai risiko rawat inap sebesar 1,25 kali lebih tinggi dibandingkan usia non risti.

Jenis kelamin $(\mathrm{p}=0,8)$ dan tingkat pendidikan $(\mathrm{p}=0,077)$ tidak berpengaruh terhadap kejadian rawat inap. Tingkat pendidikan rendah akan lebih berisiko sebesar 2,1 kali lebih tinggi untuk dirawat inap di Arab Saudi, walaupun secara statistik tidak signifikan ( $p>0,05)$.

Lama menderita DM tidak berpengaruh terhadap kejadian rawat inap ( $\mathrm{p}=0,078$ ). Dari hasil OR yang didapatkan, penderita $\mathrm{DM} \geq 9$ tahun akan lebih berisiko untuk dirawat inap sebesar 2,1 kali lebih tinggi dibandingkan yang mengidap DM $\leq 8$ tahun.

Komorbid hipertensi $(p=0,62)$ tidak berpengaruh terhadap kejadian rawat inap. Komorbid penyakit jantung $(\mathrm{p}=0,23)$ secara statistik tidak signifikan, namun penderita DM dengan komorbid penyakit jantung akan lebih berisiko sebesar 1,7 kali lebih tinggi untuk dirawat inap dibandingkan penderita DM tanpa penyakit jantung. Komorbid dislipidemia $(p=0,14)$ tidak berpengaruh terhadap kejadian rawat inap. Dari hasil OR didapatkan bahwa penderita DM dengan dislipidemia akan mempunyai risiko 2,2 kali lebih tinggi untuk dirawat inap.

Komorbid riwayat stroke $(\mathrm{p}=0,15)$ secara statistik tidak mempunyai pengaruh terhadap kejadian rawat inap. Dari hasil penelitian ini bisa disimpulkan, bahwa penderita DM dengan komorbid pernah stroke 2 kali akan berisiko 8,1 kali lebih tinggi untuk dirawat inap, dan penderita diabetes dengan komorbid riwayat stroke sekali akan mempunyai risiko sebesar 3,4 kali lebih tinggi dibandingkan penderita DM tanpa riwayat stroke.

Komorbid obesitas $(p=0,13)$ tidak berpengaruh terhadap kejadian rawat inap, namun penderita DM dengan obesitas akan mempunyai risiko 3,3 kali lebih tinggi untuk dirawat inap di Arab Saudi.

Kepatuhan diet $(\mathrm{p}<0,001)$, kepatuhan pengobatan $(p=0,029)$ dan lama hari sebelum rawat inap $(\mathrm{p}<0,001)$ secara statistik berpengaruh terhadap kejadian rawat inap. Penderita DM yang tidak patuh diet akan berisiko dirawat inap 9,1 kali lebih tinggi dibandingkan penderita DM yang sangat patuh diet. Pengobatan DM yang dilakukan dengan tidak patuh akan berisiko 3,5 kali lebih tinggi untuk dirawat inap di Arab Saudi dibandingkan penderita DM yang sangat patuh dengan pengobatannya. Durasi lama hari tinggal di Arab Saudi $\geq 20$ hari akan berisiko dirawat inap sebesar 5,2 kali lebih tinggi dibandingkan bila tinggal $\leq 19$ hari bagi penderita DM. Sedangkan variabel suhu di 
Arab Saudi $(p=0,13)$ tidak mempunyai pengaruh terhadap kejadian rawat inap jemaah DM di Arab Saudi, dan merupakan faktor protektif.

Variabel kandidat yang masuk dalam analisis multivariat $(\mathrm{p}<0,25)$ adalah tingkat pendidikan, pengetahuan, lama menderita DM, komorbid penyakit jantung, komorbid dislipidemia, komorbid stroke, komorbid obesitas, kepatuhan diet, kepatuhan pengobatan, lama hari sebelum rawat inap dan suhu di Arab Saudi. Variabel usia tetap dimasukkan dalam analisis dengan pertimbangan usia risti berpengaruh pada kejadian rawat inap. ${ }^{5-7}$

Semua variabel dianalisis bersamasama, model terbaik dipertimbangkan dengan nilai signifikan $(\mathrm{p}<0,05)$. Variabel yang mempunyai nilai signifikansi $>0,05$ dikeluarkan dari model adalah suhu di Arab Saudi $(\mathrm{p}=1,00)$ adalah komorbid obesitas $(p=1,00)$, komorbid riwayat stroke $(\mathrm{p}=1,00)$, lama hari sebelum rawat inap $(\mathrm{p}=0,998)$, komorbid penyakit jantung $(\mathrm{p}=0,862)$, tingkat pendidikan $(\mathrm{p}=0,718)$, kepatuhan pengobatan $(\mathrm{p}=0,391$ dan lama $\mathrm{DM}(\mathrm{p}=0,224)$.

Tabel 2. Hasil uji multiple logistic regression berbagai faktor yang berpengaruh terhadap kejadian rawat inap jemaah DM di Arab Saudi

\begin{tabular}{|c|c|c|c|c|c|}
\hline No & Variabel & B & Nilai $p$ & OR $(95 \% \mathrm{CI})$ & \\
\hline 1. & Komorbid dislipidemia & 1,394 & 0,055 & $4,0(0,97-16,73)$ & \\
\hline \multirow[t]{3}{*}{2 . } & $\begin{array}{l}\text { Kepatuhan diet } \\
\text { (tidak patuh }><\text { patuh) }\end{array}$ & & 0,006 & & \\
\hline & $\begin{array}{l}\text { Kepatuhan diet } \\
\text { (tidak patuh }><\text { sangat patuh) }\end{array}$ & 2,643 & 0,001 & $14,0(2,78-70,97)$ & \\
\hline & $\begin{array}{l}\text { Kepatuhan diet } \\
\text { (patuh }><\text { sangat patuh) }\end{array}$ & 22,04 & 0,999 & & - \\
\hline 3. & Usia & 0,496 & 0,336 & $1,6(0,59-4,51)$ & \\
\hline \multirow[t]{2}{*}{4.} & Pengetahuan tentang DM & 1,883 & 0,003 & $6,5(1,9-22,7)$ & \\
\hline & Konstanta & $-3,388$ & & & \\
\hline
\end{tabular}

\section{Pembahasan}

Hasil akhir analisis menggunakan uji Multiple Logistic Regression diperoleh bahwa faktor yang berpengaruh terhadap kejadian rawat inap jemaah DM di Arab Saudi, adalah kepatuhan diet dengan kategori tidak patuh $(\mathrm{OR}=14$ dan nilai $\mathrm{p}=0,001)$ dan pengetahuan DM yang kurang $(\mathrm{OR}=6,5$ dan nilai $\mathrm{p}=0,003)$.

Dari Tabel 2 dan persamaan regresi dapat disimpulkan bahwa seorang jemaah haji yang mempunyai pengetahuan kurang mengenai DM dan tidak patuh diet akan memiliki probabilitas atau risiko mengalami kejadian rawat inap di Arab Saudi sebesar $75 \%$ setelah dikontrol oleh variabel usia, jenis kelamin, tingkat pendidikan,lama menderita DM, komorbid: hipertensi, penyakit jantung, dislipidemia, riwayat stroke dan obesitas, kepatuhan pengobatan, lama hari sebelum rawat inap dan suhu di Arab Saudi.

Risiko untuk mengalami kejadian rawat inap di Arab Saudi bagi jemaah DM 
yang tidak patuh diet sebesar 14 kali lebih tinggi dibandingkan jemaah yang sangat patuh dietnya dan jemaah yang mempunyai pengetahuan kurang adalah 6,5 kali lebih tinggi daripada jemaah yang mempunyai pengetahuan tentang DM lebih baik.

Kepatuhan diet bagi jemaah haji penderita DM pada saat di Arab Saudi merupakan hal yang mutlak dilakukan, walaupun terkadang sulit untuk diterapkan. Hal tersebut disebabkan karena kesibukan beraktifitas dan beribadah, sementara pemenuhan kebutuhan makanan tidak terlalu diperhatikan dengan baik, sehingga pada saat lapar terkadang membeli makanan dengan mengabaikan diet DMnya. Dari penelitian tahun 2013 di Pekalongan, terdapat hubungan yang signifikan antara kepatuhan diet dengan kejadian kaki diabetik dengan nilai $\mathrm{p}=$ 0,030. Dalam kegiatan haji, jemaah DM yang menderita kaki diabetik akan mendapatkan perawatan dalam kloternya oleh TKHI, dan apabila bertambah parah akan segera dirujuk untuk dirawat inap. ${ }^{8}$

Dalam konsep terbaru, dikenal istilah "Health Literacy" yang bisa diterjemahkan dengan "melek kesehatan". 8 Konsep ini berarti merupakan kemampuan individu untuk membaca, memahami, dan menggunaakan informasi kesehatan dalam membuat keputusan kesehatan yang efektif serta mengikuti petunjuk untuk perawatan penyakitnya.Termasuk dalam hal ini adalah keseluruhan tentang pengetahuan penyakit yang diderita dan perilaku yang dilakukan (kepatuhan dalam melakukan diet). Perbedaan tingkat melek kesehatan, dalam hal ini pengetahuan dan perilaku penanganan (DM) secara konsisten dikaitkan dengan peningkatan rawat inap dan kunjungan gawat darurat. ${ }^{9}$

\section{Kesimpulan}

Sebagian besar responden $(63,5 \%)$ sudah lama mengidap DM (lebih dari 9 tahun). Tingkat kepatuhan responden terhadap diet DM dan kepatuhan minum obat DM sudah baik (kepatuhan diet 84,3 $\%$ dan kepatuhan pengobatan $76,5 \%$ ) yaitu pada kategori patuh. Faktor yang terbukti mempunyai pengaruh terhadap kejadian rawat inap jemaah DM di Arab Saudi adalah pengetahuan $(\mathrm{OR}=6,5 ; 95 \% \mathrm{CI}=$ 1,9-22,7) dan kepatuhan diet $(\mathrm{OR}=14,0$; $95 \% \mathrm{CI}=2,78-70,97)$.

\section{Ucapan Terimakasih}

Terimakasih kepada jajaran pimpinan dan staf di Kementerian Kesehatan; BPPSDM Kesehatan, Pusat Kesehatan Haji; Dinkes Prov. Jawa Tengah dan DIY; Kanwil Kementerian Agama Prov. Jawa Tengah dan DIY dan Kantor Kesehatan Pelabuhan Semarang yang telah memberikan sarana dan prasarananya di dalam menyelesaikan penelitian.

\section{Daftar Pustaka}

1. Kementerian Agama RI.2013. Pendaftar Capai 40 Ribu Jamaah per Bulan, Antrian Calon Jamaah Haji Indonesia Mencapai 2,2 Juta. Jakarta: Kemenag RI. 
2. Direktorat Jenderal Penyelenggaraan Haji dan Umroh Kemenag RI. Waiting List. Jakarta: Dirjen Haji dan Umroh Kemenag RI; 2015 [updated 2015; cited 201530 Juli]; Available from: http://haji.kemenag.go.id/v2/basisdata/ waiting-list.

3. Kantor KesehatanPelabuhan Semarang. 2013. Laporan Hasil Penyelenggaraan Pelayanan Kesehatan Haji Embarkasi/ Debarkasi Haji Adisumarmo Surakarta Tahun 1434 H/2013M. Semarang: KKP.pp.15.

4. Kantor KesehatanPelabuhan Semarang. 2014. Laporan Hasil Penyelenggaraan Pelayanan Kesehatan Haji Embarkasi/ Debarkasi Haji Adisumarmo Surakarta Tahun 1435 H/2014M. Semarang: KKP Semarang.pp.18-23.

5. Bo S, Ciccone G, Grassi G, Gancia R, Rosato R, Merletti F, et al. 2004. Patients with Type 2 Diabetes Had Higher Rates of Hospitalization Than The General Population. Journal of Clinical Epidemiology.pp.196-201.
6. Chen H-L, Hsiao F-Y. 2014. Risk of Hospitalization and Healthcare Cost Associated with Diabetes Complication Severity Index in Taiwan's National Health Insurance Research Database. Journal of Diabetes and Its Complications. pp. 612-616.

7. Riyanto A. 2012. Penerapan Analisis Multivariat dalam Penelitian Kesehatan. Yogyakarta: Nuha Medika. pp. 19-20.

8. Katz DL, Elmore JG, Wild DMG, Sean C. Lucan. 2014. Jekel's Epidemiology, Biostatistics, Preventive Medicine, and Public Health-Fourth Edition. Philadelphia: Elsevier Saunders.pp.193.

9. Institute of Medicine. 2004. Health Literacy: A Prescription to end Confusion. National Academies Press, Washington DC.pp.9.

10. Armenian HK.2009.The Case-Control Method, Design and Application. New York: Oxford University Press.pp.59. 